\title{
AR-based One Hand Aerial Gesture Control For Medical Applications*
}

\author{
E.P. Vasiliev $^{1}$, T. Komuro ${ }^{2}$, V.E. Turlapov ${ }^{1}$, and A. V. Nikolsky ${ }^{3}$ \\ evgeny.vasiliev@itmm.unn.ru; komuro@mail.saitama-u.ac.jp; \\ vadim.turlapov@gmail.com; yahtingman@rambler.ru \\ ${ }^{1}$ Lobachevsky University, Nizhny Novgorod, Russia; ${ }^{2}$ Saitama University, Saitama, Japan; \\ ${ }^{3}$ Municipal Clinical Hospital 5 of Nizhny Novgorod, Nizhny Novgorod, Russia
}

We consider the problem of interaction of the operating surgeon with medical software during the operations justified the need to develop a new type of interaction. We reviewed the existing methods of interaction with applications and described new method of interaction with objects in virtual three-dimensional space with one hand aerial gestures. We propose an interface that allows the user to interact with a computer model of the heart using one hand gestures, executing operations that can be performed with one hand are model moving, zooming and rotating. Using only one hand to interact with the model is more convenient for a person than using two hands. We created a demo application to show the advantages of this approach.

Keywords: aerial gestures, one hand control, gesture recognition, medical visualization, medical software

DOI: $10.21469 / 22233792.4 .2 .02$

\section{Introduction}

The problem of human-computer interaction arose already at the very beginning of information technology with the appearance of the first computers. The most popular input device nowadays is the mouse, but it has disadvantages: the mouse needs a smooth surface; it is difficult to work with it in three-dimensional space. Gesture recognition is a promising method that has both disadvantages and advantages over the mouse.

Aerial gesture recognition is an important research issue in the field of human-computer interaction, because of its extensive applications in virtual reality, sign language recognition, and computer games. Nowadays, more and more software that supports gesture input is being created [1]. Examples in the medical field include [2], communication with the operation system is investigated in [3], fitness in [4], games in [5].

Currently, there is no single standard for air hand gestures, all software developers create their own variants. By default Microsoft Kinect v2 can recognize only 3 types of gestures: opened hand, closed hand and lasso. Leap Motion can recognize aerial hand gestures only at a short distance. Recognizing the gestures of just one hand can make the input system more versatile.

\section{Problem description}

Cardiac interventional arrhythmologist during surgery of eliminating arrhythmias needs a high attention and concentration. A surgeon simultaneously observes instrument readings from several monitors and display panels of electrophysiological laboratory systems, including heart navigation system (Figure 1). Most important measurements are: real time changes of the heart electrocardiogram and endogram; measurements of time, energy and temperature of exposure on the radiofrequency generator or cryogenerator, and 3-dimentional visualization of heart cavities mapping by navigation system.

${ }^{*}$ The research was supported by the Ministry of Education and Science of Russia Contract 02.G25.31.0157. 


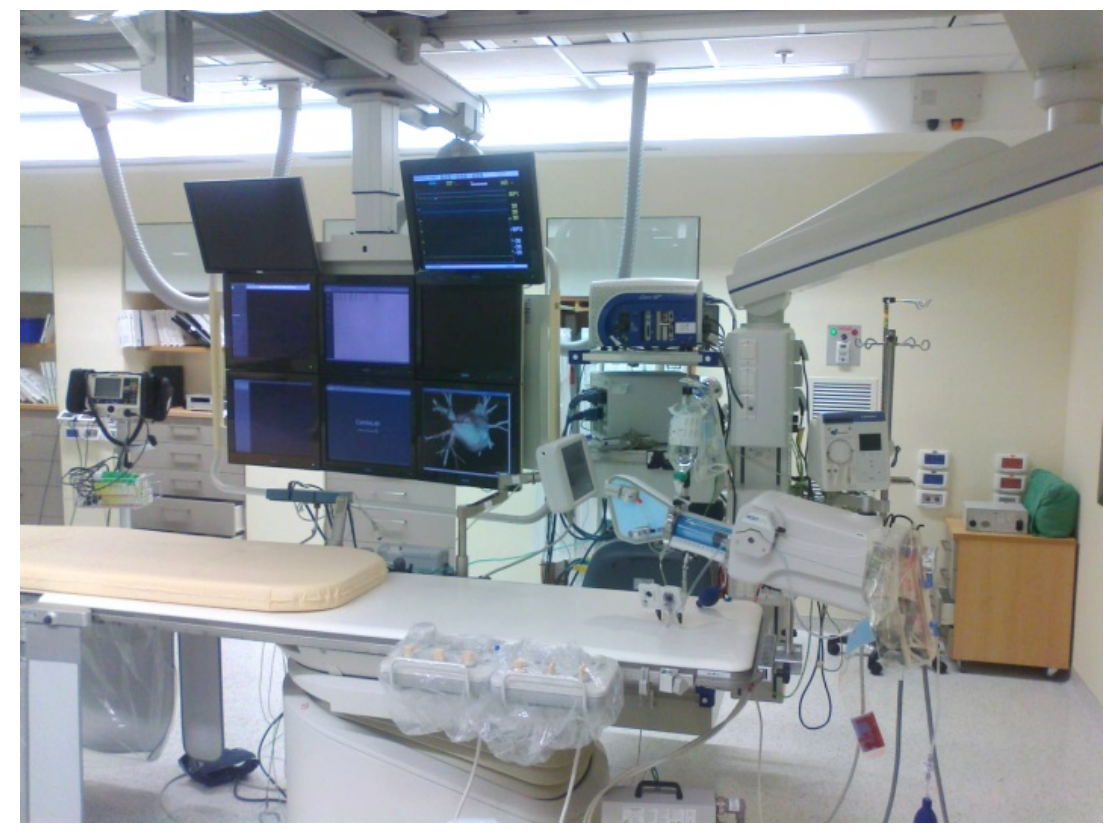

Figure 1 Medical system "Cartoß 3"installed in Medical center in Nizhniy Novgorod, Russia.

During the surgery operation cardiac interventional arrhythmologist needs to see different angles of heart navigation model to choose optimal position of catheters in the heart cavities. Nowadays there are two widespread ways of the heart model positioning: 1) the surgeon with voice commands ask the assistant to change angle of heart model view; 2) the surgeon uses wireless mouse packed in sterile pouch.

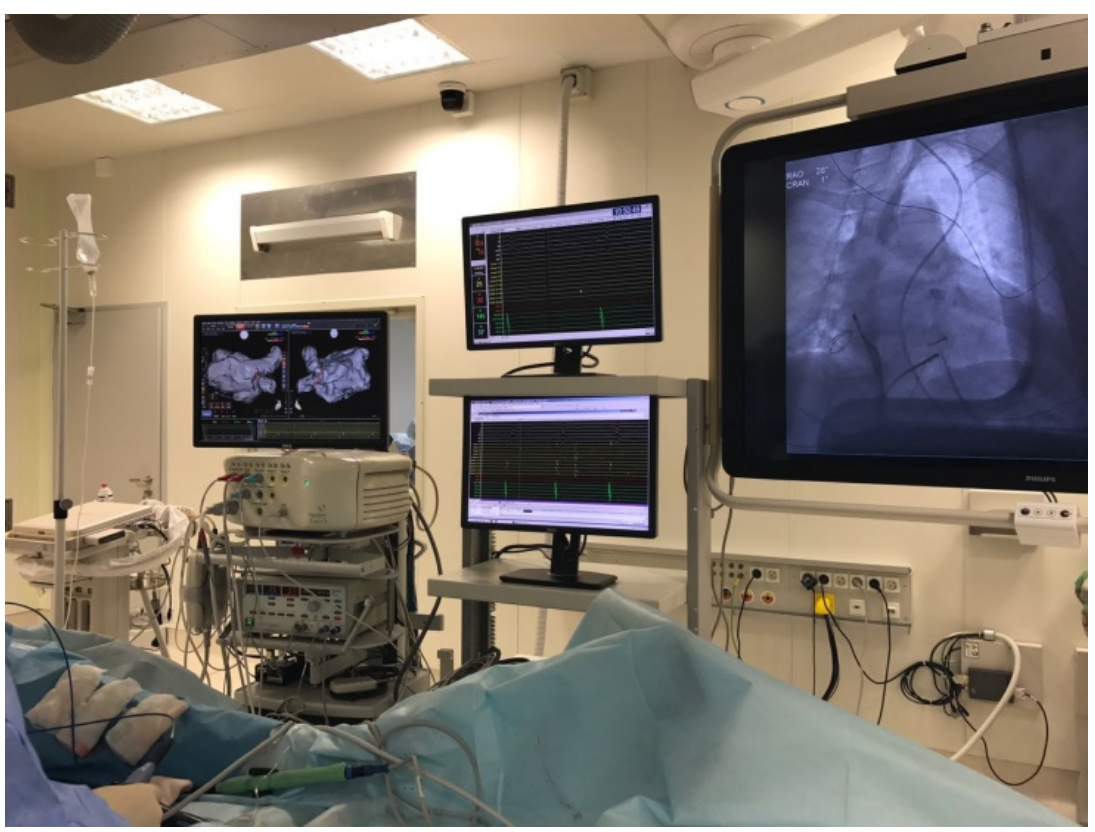

Figure 2 Indicators used by the surgeon during the operation: 3D heart model, electrocardiogram, endogram.

Both ways have disadvantages. The main problem of the first way is that the surgeon depends on his assistant. The assistant must be highly qualified to understand what angle the 
arrhythmologist wants to see, voice commands connection also takes a lot of time and distracts from a medical operation (Figure 3). The second variant also has limitations: the surgeon has to control mouse position to avoid accidental model movements, to change the direction of view between the patient, the screen and the mouse.

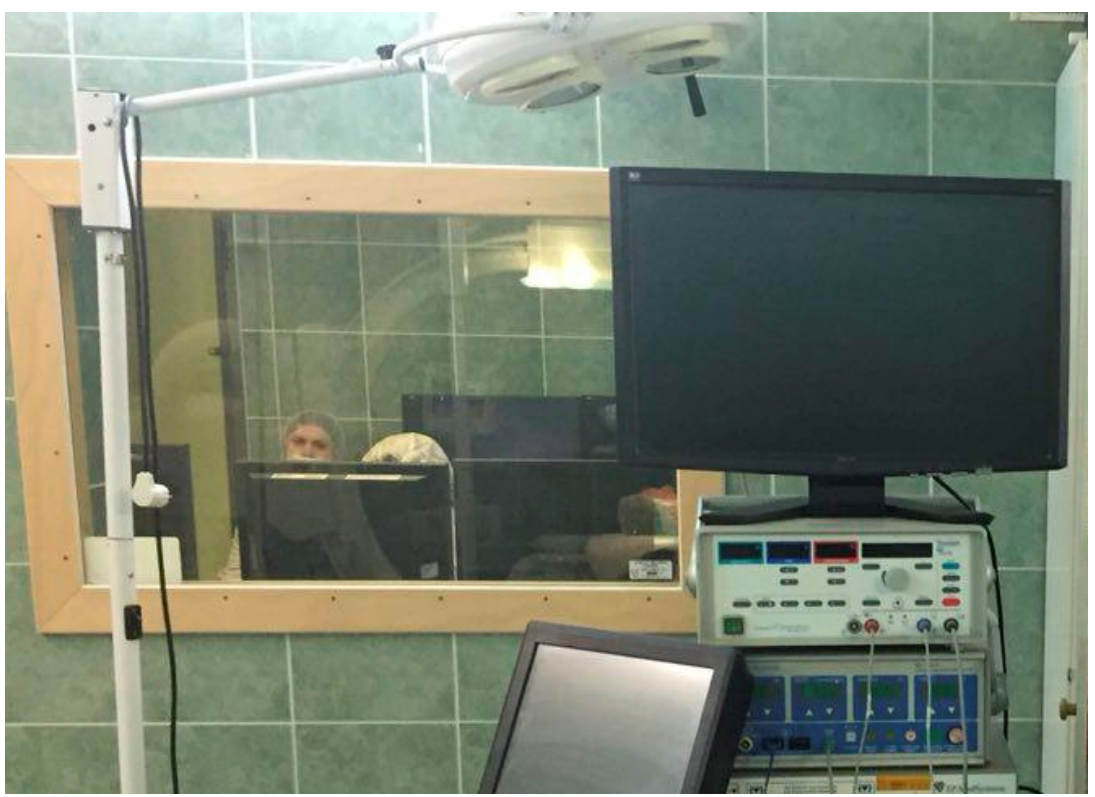

Figure 3 Arrhythmologist's assistant (on the left side in the window) operates with navigation system remote control in Nizhniy Novgorod Medical Center.

The perspective type of interaction for surgery uses an aerial one-hand gesture recognition. Using gestures for interaction with navigation system simplifies and optimizes the operation procedure.

The very important advantage for the arrhythmologist is the usage of only one hand for interaction, because the surgeon is able to continue to hold and to manage the catheter by left hand and interact with the patient's heart model by right hand. The usage of the air hand gesture manipulation will shorten the time of medical operation and will increase the comfort of surgery for the cardiovascular surgeon.

\section{Description of one-hand gesture control}

To interact with the most commonly used objects in real life - smartphones, keys, pens, door handles, etc. - people use only one hand. The most natural gesture for the hand is grabbing. So that would make complete sense to use it in applications. The most popular aerial gesture recognition libraries already support grabbing. Grabbing is very similar to clicking the left mouse button, and it is necessary to bind functions related to the click, for example, moving, zooming and rotating in the application interface.

During decades of software development, convenient 2D interfaces were created to interact with graphics software. This kind of interaction has become a standard in graphics software, and using this approach for the $3 \mathrm{~d}$ interface is a good idea.

The key idea of this type of interaction is different actions, which are applied depending on the position of the cursor relative to the object for interaction. 


\subsection{D interaction with objects by aerial gestures}

We created an interface that is to the 2D version for the convenience of the user, but allows interacting with objects in three-dimensional space. The basic approach to create the interface is to simply imitate the real, physical world as closely as possible. The advantage of the "copying the real-world" approach is that the user already knows how to use the interface from everyday experience.
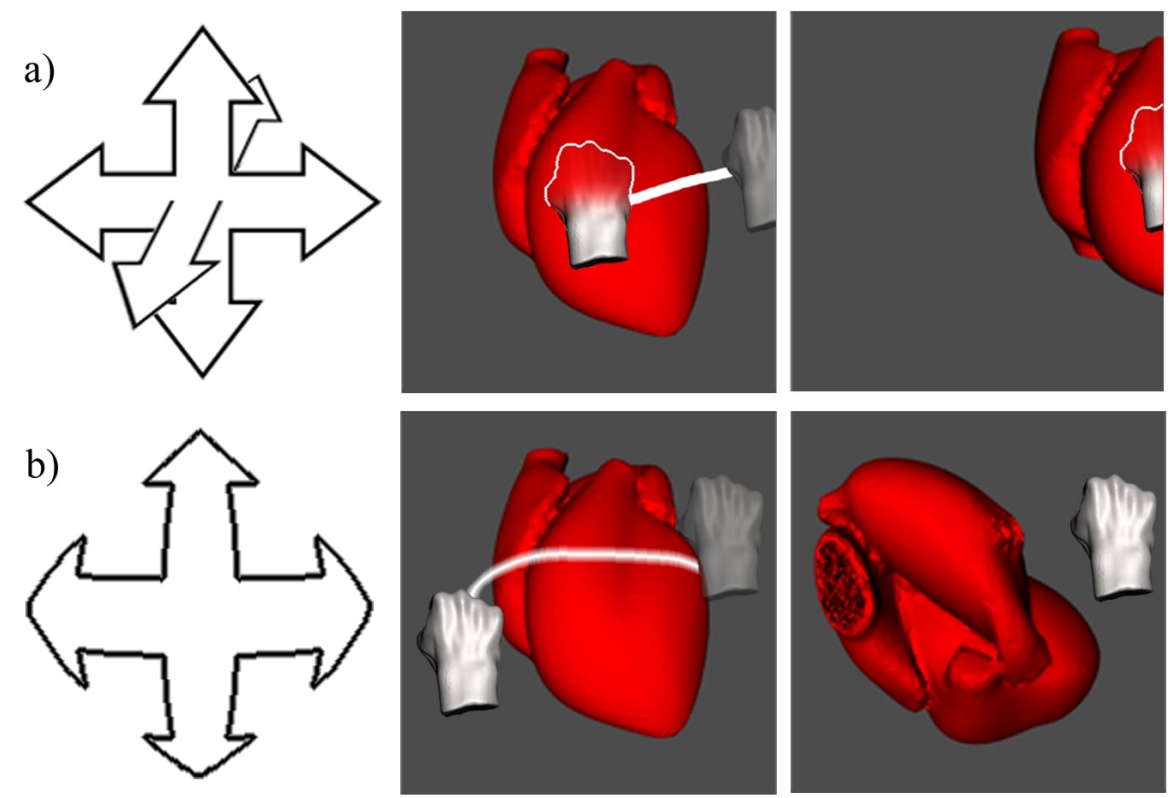

c)
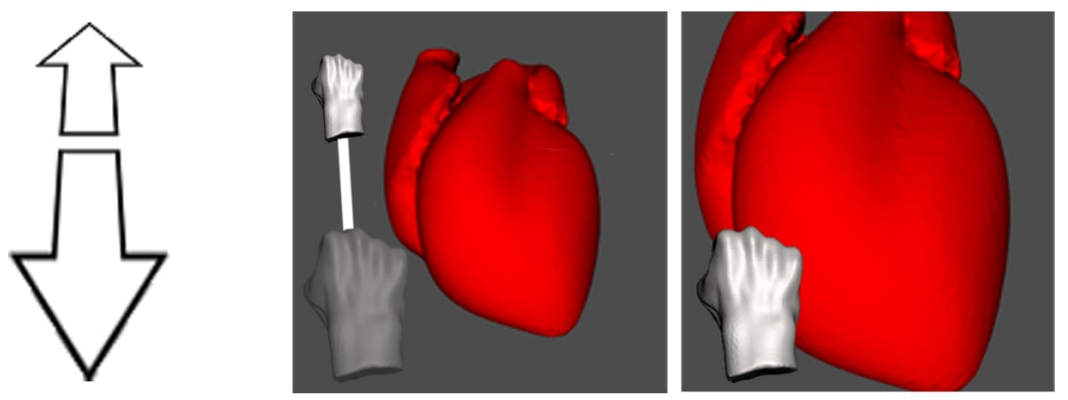

Figure 4 Aerial hand gestures. a) Moving; b) Rotating; c) Zooming.

In our proposed variant of interaction, the approach from the article about 3D view navigation by aerial hand gestures [6] was expanded. The type of applied action depends on the position of the hand during the gripping operation. If the hand is inside the model, then the object is dragged (Figure 4,a). The direction of dragging coincides with the direction of the movement of the hand in three directions. Dragging is performed until the user clenches his fist.

If the hand is located outside the model, zooming or rotating is applicable. The movement of the fist to the right / left or up / down causes the heart model rotation in this direction (Figure 4,b).

The movement of the hand diagonally activates both directions of rotation. Zooming (heart model size change) is performed when the user moves the clenched fist towards or away from the camera (Figure 4,c). 


\subsection{Hand image overlay}

The pointer is a very important part of the gesture recognition system, especially in most 3D settings. It depends on the cursor how quickly the user can get used to interacting with the program. We described the following pointers:

- without pointer. This option is suitable for touch panels, because in this case the user's finger acts as pointer;

- simple dot. Easy to create, but not very descriptive, especially when moving in three dimensions;

- virtual hand. Very descriptive in 3D space, but very difficult to create, off the shelf implementation is not available.

We created an intermediate version of the cursor. We retrieve the depth image from the Kinect depth camera, cut the subimage with the hand, and create a hand points cloud. This model is practical and easy to create (Figure 5).

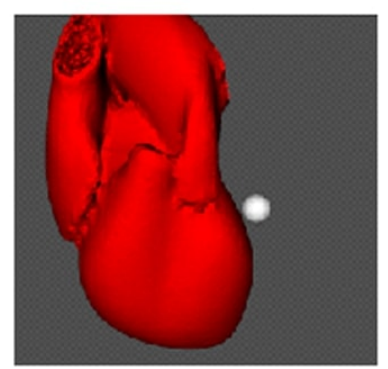

a)

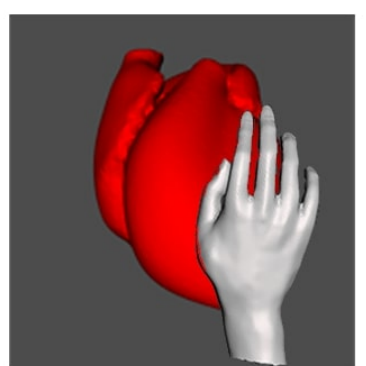

b)

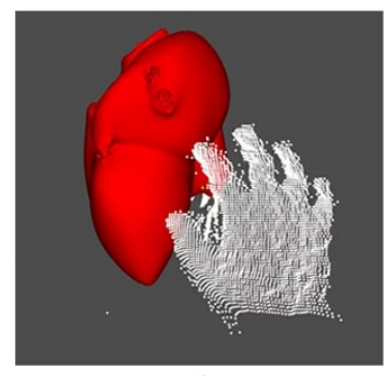

c)

Figure 5 Types of cursor. a) Simple dot. b) Virtual hand. c) Depth image projection.

The advantage of this method is that the user sees the image of his hand. This makes the interaction with the program more realistic for the user.

\section{Implementation}

We implemented the one hand interface on a demonstration system. The configuration of the prototype is shown in Figure 5. A standard desktop PC with 23 inch Full HD monitor was used for the prototype. The source of the hand data was the Kinect v2 sensor placed on the monitor for obtaining aerial hand gestures (Figure 6).

The depth images captured by Kinect were $512 \mathrm{x} 424$ pixels, the frame rate was $30 \mathrm{fps}$. The best recognition quality was observed at a distance of 1-2 meters. To recognize gestures, the application used the Kinect SDK, which is supplied with the Kinect device. To visualize the object, Visualization Toolkit (VTK), an open-source framework for 3D computer graphics, image processing and visualization was used. The model mesh consisted of an unstructured grid of tetrahedrons. The number of points was 159654, the number of tetrahedrons 750432 .

\section{Conclusion}

This paper presents a method of interaction with application for gesture recognition of an image from a depth camera. We described a way to transform gestures into control commands to move, rotate and resize the model. Using this interaction, this model allows users to interact with objects in a three-dimensional virtual space. 


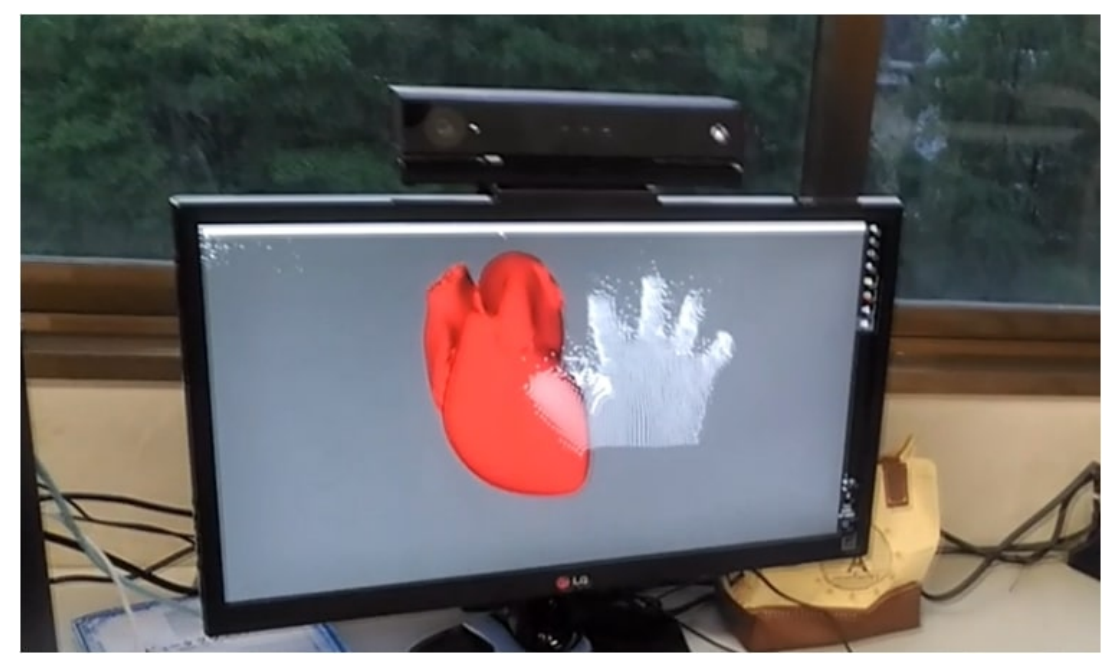

Figure 6 Hand gestures for rotate, resize and move operations.

The future work includes the creation of a cursor in the form of a solid hand model and recognition of the rotation of the gripping hand.

\section{References}

[1] A Mewes et al. Touchless Interaction with Software in Interventional Radiology and Surgery: A Systematic Literature Review. International Journal of Computer Assisted Radiology and Surgery, volume 12 (2), 291-305. Springer, Heidelberg (2017). doi:10.1007/ s13244-018-0620-7

[2] Tan JH., Chao C., Zawaideh M., Roberts AC., Kinney TB. Informatics in radiology: developing a touchless user interface for intraoperative image control during interventional radiology procedures. RadioGraphics, volume 33(2), 61-70. (2013). doi:10.1148/rg. 332125101

[3] Rod Furlan. The future of augmented reality: Hololens - Microsoft's AR headset shines despite rough edges. IEEE Spectrum. Volume: 53 Issue: 6, IEEE Spectrum, New York (2016). doi: 10.1109/MSPEC. 2016.7473143

[4] Gillian Barry. Exergaming (XBOX Kinect ${ }^{\mathrm{TM}}$ ) versus traditional gym-based exercise for postural control, flow and technology acceptance in healthy adults: a randomised controlled trial. BMC Sports Science, Medicine and Rehabilitation, (2016). doi:10.1186/s13102-016-0050-0

[5] O’Donovan C., Hirsch E., Holohan E., McBride I., McManus R., Hussey J. Energy expended playing Xbox Kinect ${ }^{\mathrm{TM}}$ and Wii ${ }^{\mathrm{TM}}$ games: a preliminary study comparing single and multiplayer modes. Physiotherapy, volume 98(3):224-229. Elsevier, Dublin (2012). doi:10.1016/j.physio. 2012.05 .010

[6] S. Sekiguchi, T. Komuro. VolGrab: Realizing 3D View Navigation by Aerial Hand Gestures. CHI 2017 Extended Abstracts, 2064-8. ACM New York (2017). doi:10.1145/3027063.3053108 


\title{
Жестовое управление дополненной реальностью при кардиологических интервенциях*
}

\author{
Е.П. Васильев ${ }^{1}$, Т. Комуро, ${ }^{2}$, В. Е. Турлапов ${ }^{1}$, А. В.Никольский ${ }^{3}$ \\ evgeny.vasiliev@itmm.unn.ru; komuro@mail.saitama-u.ac.jp; \\ vadim.turlapov@gmail.com; yahtingman@rambler.ru
}

${ }^{1}$ ННГУ им. Н.И. Лобачевского, 603950, Нижегородская область, г. Нижний Новгород, пр.Гагарина, 23; ${ }^{2}$ Университет Сайтама, Япония; ${ }^{3}$ Городская клиническая больница №5 г.

Нижнего Новгорода, 603005, Нижегородская область, г. Нижний Новгород, ул. Нестерова, 34.

Работа интервенционного кардиолога аритмолога сопряжена с высокой концентрацией внимания в ходе операции по устранению аритмий. Врач одновременно контролирует показатели нескольких мониторов и индикаторных панелей приборов ЭФИ (электрофизиологической) лаборатории и навигационной системы (Carto). Мы предлагаем интерфейс, который позволяет пользователю взаимодействовать с трехмерной моделью сердца, при помощи жестов, которые могут выполняться одной рукой без взаимодействия с мышью и другими физическими устройствами ввода, и таким образом перемещать, масштабировать и вращать модель. Использование только одной руки для взаимодействия с моделью более удобно для человека, чем использование двух рук, а в определенных ситуациях является едиственно возможным типом взаимодействия. В ходе исследований было создано демонстрационное приложение, чтобы показать преимущества этого подхода.

Ключевые слова: управление жестами; распознавание жестов; дополненная реальность; медицинская визуализачия

DOI: $10.21469 / 22233792.4 .2 .02$

\section{Литература}

[1] A Mewes et al.. 2017. Touchless Interaction with Software in Interventional Radiology and Surgery: A Systematic Literature Review International Journal of Computer Assisted Radiology and Surgery 12 (2), 291-305. doi: http://dx.doi.org/10.1007/s13244-018-0620-7

[2] Tan JH., Chao C., Zawaideh M., Roberts AC., Kinney TB.. 2013. Informatics in radiology: developing a touchless user interface for intraoperative image control during interventional radiology procedures RadioGraphics 33(2), 61-70. doi: http://dx.doi.org/10.1148/rg. 332125101

[3] R. Furlan. . 2016. The future of augmented reality: Hololens - Microsoft's AR headset shines despite rough edges IEEE Spectrum 53 (6). doi: http://dx.doi.org/10.1109/MSPEC. 2016. 7473143

[4] G. Barry. 2016. Exergaming (XBOX Kinect ${ }^{\mathrm{TM}}$ ) versus traditional gym-based exercise for postural control, flow and technology acceptance in healthy adults: a randomised controlled trial. BMC Sports Science, Medicine and Rehabilitation doi: http://dx.doi.org/10.1186/ s13102-016-0050-0

[5] O'Donovan C., Hirsch E., Holohan E., McBride I., McManus R., Hussey J.. 2012. Energy expended playing Xbox Kinect ${ }^{\mathrm{TM}}$ and Wii ${ }^{\mathrm{TM}}$ games: a preliminary study comparing single and multiplayer modes Physiotherapy 98(3), 224-229. doi: http://dx.doi.org/10.1016/j.physio. 2012.05.010

[6] S. Sekiguchi, T. Komuro.. 2017. VolGrab: Realizing 3D View Navigation by Aerial Hand Gestures. CHI 2017 Extended Abstracts 2064-8. doi: http://dx.doi.org/10.1145/3027063.3053108

* Работа поддержана Министерством Образования и Науки Российской Федерации (Контракт № 02.G25.31.0157) 
Поступила в редакцию 12.09.2018 